\title{
Analysis on Evolutionary Game of Parking Standardization of Sharing Bike
}

\author{
Honghong Zhang ${ }^{1, a}$, Hongzhen Lei ${ }^{1, \text { b }}$, Juanli Lan ${ }^{1, c}$, chao Liu ${ }^{1, d}$ \\ ${ }^{1}$ School of International Business, Shaanxi Normal University \\ Xian 710119, China \\ a1677863559@qq.com, bleihongzhen@snnu.edu.cn, ${ }^{\mathrm{c} l a n j u a n l i m u t o u @ 163 . c o m, ~}{ }^{\mathrm{d}} 1010273520 @ \mathrm{qq} . c 0 m$
}

\begin{abstract}
In order to solve the problem of parking standardization of sharing bike, this paper establishes an evolutionary game model for government and enterprises based on the current parking standardization of sharing bike, analyzes the stability of both parties, and reveals the effect of its stability. The research shows the following results: the government performance evaluation coefficient will not affect the behaviors of both parties; raising the standard of government regulation and strengthening government regulation will promote the strict enterprise management; it is conducive to strict government supervision by raising the standard of government regulation and intensifying punishment. The government should appropriately increase the punishment for non-strict governance of the enterprise and reduce its own supervision cost, so as to prevent the government and enterprise from falling into an infinite loop in policy selection.
\end{abstract}

Keywords-Sharing bike; Parking standardization; Evolutionary game; The government supervision; Enterprise management; Government supervision

\section{INTRODUCTION}

Bike sharing refers to enterprises cooperate with the government to provide bicycle sharing services in campus, subway stations, bus stations, residential areas, commercial areas, public service areas, etc, and is a kind of new form of Shared economy. In campus, subway stations, bus stations, residential areas, commercial areas, public service areas, etc. Since the end of 2016, domestic bike sharing has suddenly become popular .on the streets, as if overnight, bike sharing has come to the point where "flood", every large city roadside filled with a variety of color bikes sharing. At the beginning of 2017, the governments began to investigate and control the problem of sharing bikes in random parking and occupying urban public space.

\section{LITERATURE REVIEW}

The rapid development of bike sharing has attracted the attention and discussion of many scholars. Yijin Zhang (2017) according to some negative externalities of bike sharing, using evolutionary game theory to establish the stability strategy analysis model between the government and bike sharing platforms, analysis the dynamic evolution process, discusses the choice of behavioral strategy under different stability conditions [1]. Site Fu (2017) studies the parking model for bikes sharing, such as: simple bicycle frame, intelligent parking spot and three-dimensional bike sharing garage [2]. lifan Deng
(2017) used spatial statistical methods to compare and analyze the cycling demands and spatial distribution characteristics of bike sharing around subway stations and conventional bus stations, as well as the cycling demands and spatial distribution characteristics of bike sharing around residential, office, culture and education and sports 13 class space elements. It plays an important role in guiding the planning of parking facilities of urban bike sharing, regulating the management of bike parking and allocation, and improving the urban public transportation system [3]. Ran Liu (2018) proposed that it would be an inevitable trend to solve the problem of negative externalities of bike sharing to explore cooperative governance among government, enterprises and customers [4]. liuhua Yang (2018) started from social psychology, and on the basis of the theory of planned behavior, introduced the situational variable of bike sharing -- consequence perception and system perception, built the extensional model of the theory of planned behavior, to explore the relationship between user behavioral attitude, subjective norm, perceived behavioral control, consequence perception and system perception and behavior consciousness to regularly park. The research results show that perceptual behavior control and consequence perception are the most important variables that affect users' parking cooperation intention [5]. shenyong $\mathrm{Hao}(2018)$ proposed that electronic fence technology may be a technical means to solve the problem of bike sharing which parked uncanonical, but the application of this technology requires a lot of supporting policies to be promoted together [6].

Each have emphasize particularly on existing research results, some scholars have classified the negative externalities (disorderly parking, serious damage, privatization, etc) of bike sharing as one kind of problem to study it. Some scholars have also studied some negative externalities of bike sharing, such as parking problems of bike sharing. In this paper, on the premise of a situation of bike sharing parking and establish a evolutionary game model between the government and the enterprise, and studies the factors influencing the stability strategy of enterprises and governments, and puts forward relevant suggestions, so as to provide a meaningful decisionmaking reference for the development of bike sharing enterprises and government supervision. 


\section{EVOLUTIONARY GAME MODEL}

This part mainly constructs the game payment matrix between the government and enterprises, and analyzes the evolutionary stability strategy in various situations through jacobian matrix.

\section{A. Game Payment Matrix}

Evolutionary games can explain economic phenomena more accurately than traditional games, in the process of repeated game, the best strategy is not found in every game, but keep learning and try to adjust strategy according to the experience, all participants will tend to be a stable strategy and achieve equilibrium, namely the evolutionary stable strategy. In this paper, government regulatory authorities (L) and bike sharing enterprises (E) are randomly selected. The following is an analysis of its evolutionary game.

There is a situation of disorderly parking of enterprise-led bike sharing. Enterprises can choose either strict governance or not strict governance. The strategy set is \{ strict governance, not strict governance . The governments can choose to enforce the law at a higher frequency and in accordance with the standard penalty, or they can choose to enforce the law at a lower frequency and lower the standard penalty, its strategy sets \{strict supervision, not strict supervision\}.Let's say the government has a standard for measuring whether it's regulated for bike sharing of enterprise, the management of enterprise will be assessed.

Variable setting of payment function: Set e for the decrease of not normatively parking bike sharing, $\mathrm{q}$ is the total amount of unstandardized parking bike sharing, $\mathrm{k}$ is the standard coefficient of normatively parking bike sharing by the government, $\lambda 1$ is the degree of strict supervision by the government $\left(0 \leq \lambda_{1}<1\right)$,in terms of payment level, it indicates the decrease of supervision cost and supervision intensity. $\lambda 2$ is the degree of corporate governance $\left(0 \leq \lambda_{2}<1\right)$, at the level of payment, it represents the reduction in the cost and intensity of governance.a is the assessment coefficient for the government to assess corporate governance performance. Namely, ae represents the social benefits of strict corporate governance, kh1 is a fine imposed by the government on enterprise when it is strictly governed.

Let's say the probability that the government will exercise strict oversight is $\mathrm{x}$, the probability of not strictly monitoring is 1-x.Assuming that the probability of strict governance is $y$, the probability of non-strict governance is 1-y.The game payment matrix between the government and enterprise is shown in tab Table. 1;

TABLE I. GAME PAYMENT MATRIX BETWEEN THE GOVERNMENT AND ENTERPRISE

\begin{tabular}{|c|c|}
\hline $\begin{array}{c}\text { Strict government supervision } \\
(\mathbf{x})\end{array}$ & $\begin{array}{l}\text { Non-strict government supervision } \\
(1-\mathrm{x})\end{array}$ \\
\hline \multicolumn{2}{|l|}{ Strict enterprise governance $\quad L-k h_{1}-C_{2}}$, \\
\hline$(\mathbf{y}) \quad a e+k h_{1}-C_{1}$ & $a e+\lambda_{1} k h_{1}-\lambda_{1} C_{1}$ \\
\hline \multicolumn{2}{|c|}{ non-strict enterprise governance $\lambda_{2} L-k h_{2}-\lambda_{2} C_{2}$, } \\
\hline $\begin{array}{ll}(1-y) & a \lambda_{2} e+k h_{2}-C_{1}\end{array}$ & $a \lambda_{2} e+k \lambda_{1} h_{2}-\lambda_{1} C_{1}$ \\
\hline
\end{tabular}

Suppose that the expected benefits of "strict regulation" and "non-strict regulation" by the government are respectively: Et1 and Et2, and average return is E1, namely:

$$
\begin{aligned}
& \mathrm{E}_{\mathrm{t} 1}=y\left(a e+k h_{1}-C_{1}\right)+(1-y)\left(a \lambda_{2} e+k h_{2}-C_{1}\right) \\
& \mathrm{E}_{\mathrm{t} 2}=y\left(a e+k \lambda_{1} h_{1}-\lambda_{1} C_{1}\right)+(1-y)\left(a \lambda_{2} e+k \lambda_{1} h_{2}-\lambda_{1} C_{1}\right) \\
& \overline{\mathrm{E}_{1}}=\mathrm{xE}_{\mathrm{t} 1}+\left(1-\mathrm{x}_{\mathrm{t}}\right)
\end{aligned}
$$

The government's replication dynamic equation of "strict supervision" established is as follows:

$$
\mathrm{F}(\mathrm{x})=\frac{\mathrm{dx}}{\mathrm{dt}}=\mathrm{x}\left(\mathrm{E}_{11}-\overline{\mathrm{E}_{1}}\right)=\mathrm{x}(1-\mathrm{x})\left(1-\lambda_{1}\right)\left[-y k e\left(1-\lambda_{2}\right)+\left(k h_{2}-C_{1}\right)\right]
$$

Suppose that the expected benefits of "strict governance" and "non-strict governance" by the enterprise are respectively: $\mathrm{Et} 3$ and $\mathrm{E}_{\mathrm{t} 4}$, and average return is $\mathrm{E}_{2}$, namely:

$$
\begin{aligned}
& E_{t 3}=x\left(L-k h_{1}-C_{2}\right)+(1-x)\left(L-k \lambda_{1} h_{1}-C_{2}\right) \\
& E_{t 4}=x\left(\lambda_{2} L-k h_{2}-\lambda_{2} C_{2}\right)+(1-x)\left(\lambda_{2} L-k \lambda_{1} h_{2}-\lambda_{2} C_{2}\right) \\
& \overline{\mathrm{E}_{2}}=\mathrm{y} \mathrm{E}_{\mathrm{t} 3}+(1-\mathrm{y}) \mathrm{E}_{\mathrm{t} 4}
\end{aligned}
$$

The enterprise's replication dynamic equation of "strict governance" established is as follows:

$$
\mathrm{F}(\mathrm{y})=\frac{\mathrm{dy}}{\mathrm{dt}}=\mathrm{y}\left(\mathrm{E}_{3}-\mathrm{E}_{2}\right)=\mathrm{y}(1-\mathrm{y})\left(1-\lambda_{2}\right)\left[x\left(1-\lambda_{1}\right) k e-\left(C_{2}-L-\lambda_{1} k e\right)\right]
$$

\section{B. discussion of evolutionary game parameters}

If equations (1) and (2) are set to 0 , the five local equilibrium points of the system can be solved, which are: $\mathrm{A}(0,0), \mathrm{B}(0,1), \mathrm{C}(1,0), \mathrm{D}(1,1), \mathrm{E}\left(\mathrm{X}_{0}, \mathrm{Y}_{0}\right)$, make $\mathrm{X}_{0}=, \mathrm{Y}_{0}=$,Frideman (1998) believed that the stability of the group dynamic equilibrium points described in the differential equation system could be obtained by the local stability of jacobi matrix of the system [7].

According to formula (1) and (2), the partial derivatives of $\mathrm{x}$ and $\mathrm{y}$ are obtained successively, and the jacobian matrix of the system can be obtained:

$$
J=\left[\begin{array}{l}
\frac{\partial \mathrm{F}(\mathrm{x})}{\partial \mathrm{x}} \frac{\partial \mathrm{F}(\mathrm{x})}{\partial \mathrm{y}} \\
\frac{\partial \mathrm{F}(\mathrm{y})}{\partial \mathrm{x}} \frac{\partial \mathrm{F}(\mathrm{y})}{\partial \mathbf{y}}
\end{array}\right]=\left[\begin{array}{l}
A_{11} A_{12} \\
A_{21} A_{22}
\end{array}\right]
$$

$$
\begin{aligned}
& \mathrm{A}_{11}=(1-2 x)\left(1-\lambda_{1}\right)\left[-y k e\left(1-\lambda_{2}\right)+\left(k h_{2}-C_{1}\right)\right] \\
& \mathrm{A}_{12}=-\mathrm{x}(1-\mathrm{x})\left(1-\lambda_{1}\right)\left(1-\lambda_{2}\right) k e \\
& \mathrm{~A}_{21}=\mathrm{y}(1-\mathrm{y})\left(1-\lambda_{1}\right)\left(1-\lambda_{2}\right) k e \\
& A_{22}=(1-2 y)\left(1-\lambda_{2}\right)\left[x\left(1-\lambda_{1}\right) k e-\left(C_{2}-L-\lambda_{1} k e\right)\right]
\end{aligned}
$$

The corresponding determinant and trace of the matrix are:

$$
\begin{aligned}
& \operatorname{det} J=(1-2 x)\left(1-\lambda_{1}\right)\left[-y k e\left(1-\lambda_{2}\right)+\left(k h_{2}-C_{1}\right)(1-2 y)\left(1-\lambda_{2}\right)\left[x\left(1-\lambda_{1}\right) k e-\left(C_{2}-L-\lambda_{1} k e\right)\right]\right. \\
& +\left[-x(1-x)\left(1-\lambda_{1}\right)\left(1-\lambda_{2}\right) k e\right] y(1-y)\left(1-\lambda_{1}\right)\left(1-\lambda_{2}\right) k e \\
& \text { tr.J }=(1-2 x)\left(1-\lambda_{1}\right)\left[-y k e\left(1-\lambda_{2}\right)+\left(k h_{2}-C_{1}\right)\right] \\
& +(1-2 y)\left(1-\lambda_{2}\right)\left[x\left(1-\lambda_{1}\right) k e-\left(C_{2}-L-\lambda_{1} k e\right)\right]
\end{aligned}
$$


TABLE II. SYSTEM JACOBIAN ANALYSIS

\begin{tabular}{|c|c|c|}
\hline Equilibrium point & $\operatorname{det} . J(>0)$ & $\operatorname{tr} . \mathrm{J}(<0)$ \\
\hline $\mathrm{A}(0,0)$ & $\left(1-\lambda_{1}\right)\left(k k_{2}-C_{1}\right)\left(1-\lambda_{2}\right)\left(L+\lambda_{1} k e-C_{2}\right)$ & $\left(1-\lambda_{1}\right)\left(k h_{2}-C_{1}\right)+\left(1-\lambda_{2}\right)\left(L+\lambda_{1} k e-C_{2}\right)$ \\
\hline $\mathrm{B}(0,1)$ & $-\left(1-\lambda_{1}\right)\left(k h_{1}-C_{1}\right)\left(1-\lambda_{2}\right)\left(L+\lambda_{1} k e-C_{2}\right)$ & $\left(1-\lambda_{1}\right)\left(k h_{1}-C_{1}\right)-\left(1-\lambda_{2}\right)\left(L+\lambda_{1} k e-C_{2}\right)$ \\
\hline $\mathrm{C}(1,0)$ & $-\left(1-\lambda_{1}\right)\left(k k_{2}-C_{1}\right)\left(1-\lambda_{2}\right)\left(L+k e-C_{2}\right)$ & $-\left(1-\lambda_{1}\right)\left(k h_{2}-C_{1}\right)+\left(1-\lambda_{2}\right)\left(L+k e-C_{2}\right)$ \\
\hline $\mathrm{D}(1,1)$ & $-\left(1-\lambda_{1}\right)\left(k h-C_{1}\right)\left[-\left(1-\lambda_{2}\right)\left(L+k e-C_{2}\right)\right]$ & $-\left(1-\lambda_{1}\right)\left(k h_{1}-C_{1}\right)-\left(1-\lambda_{2}\right)\left(L+k e-C_{2}\right)$ \\
\hline $\mathrm{E}(\mathrm{X} 0, \mathrm{Y} 0)$ & $\frac{\left(L+\lambda i k e-C_{2}\right)\left(L+k e-C_{2}\right)\left(k h-C_{1}\right)\left(k h-C_{1}\right)}{k e k e}$ & 0 \\
\hline
\end{tabular}

If the equilibrium point of evolutionary game satisfies det.j $>$ and tr.j $<0$, then the equilibrium point is stable, if det.j $>$ and tr.j $=0$, the equilibrium point is the center; if det.j $>0$ and tr.j $>0$, the equilibrium point is the unstable point; if det.j $<0$ and tr.j is not certain, the equilibrium point is the saddle point, available in Table. 2 :

TABLE III. EVOLUTIONARY STABILIZATION STRATEGY OF THE GOVERNMENT AND ENTERPRISE

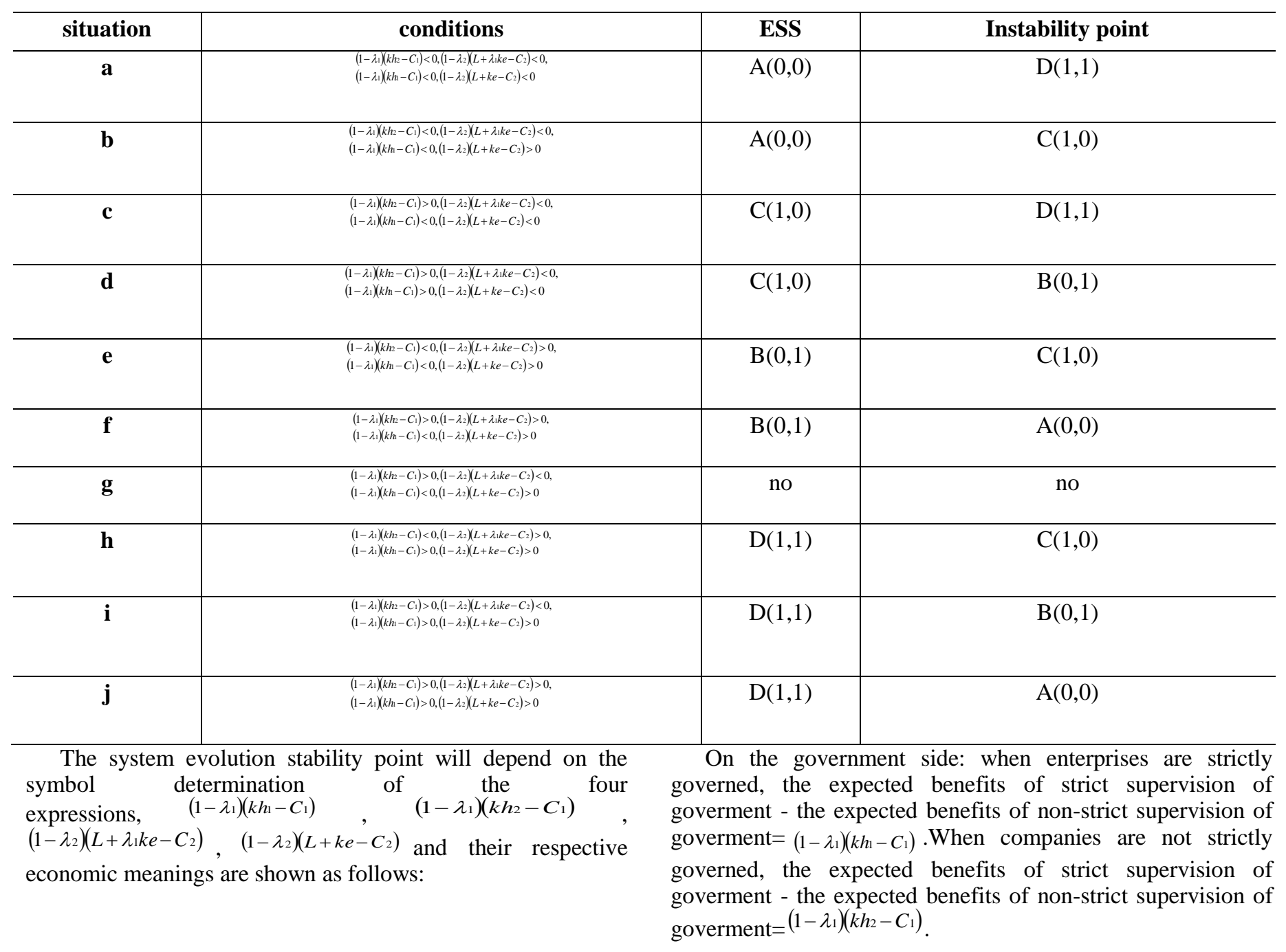


In the enterprise aspect: when the government strictly supervises, the expected benefit of strict management of the enterprise - the expected benefit of non-strict management of the enterprise $=\left(1-\lambda_{2}\right)\left(L+k e-C_{2}\right)$. When the government does not strictly supervise, the expected benefit of strict management of the enterprise - the expected benefit of nonstrict management of the enterprise $=\left(1-\lambda_{2}\right)\left(L+\lambda_{1} k e-C_{2}\right)$.

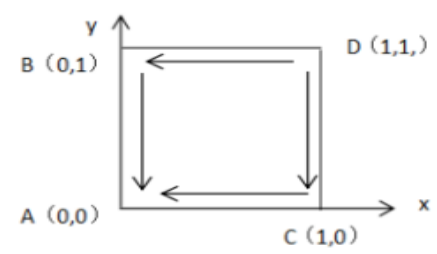

Fig. 1. Phase evolution of state a

a: When in state a, point $\mathrm{D}(1,1)$ is the source point of instability, and point $\mathrm{A}(0,0)$ is the evolutionary stability point (ESS) (see Tab III), the decision-making process of both sides of the game: On the government side: the government finds that no matter what strategy companies adopt, the expected return of the government's strict supervision is always smaller than that of the non-strict supervision. At this time, the government is more inclined to choose the non-strict supervision. On the enterprise side: enterprise find that no matter what the government's strategy, the expected return when the enterprise is strict is always smaller than that when the enterprise is not strict, then the enterprise is more inclined to choose not strict governance. The evolutionary stability strategy is (non-strict supervision, on-strict supervision), and the corresponding evolutionary dynamic phase of the system is shown in Fig 1;

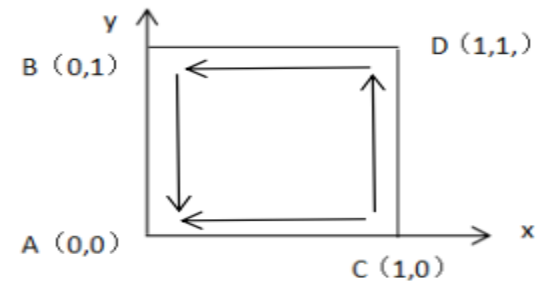

Fig. 2. phase evolution of state $b$

$\mathrm{b}$ : When in state $\mathrm{b}$, point $\mathrm{C}(1,0)$ is the source point of instability, and point $\mathrm{A}(0,0)$ is the evolutionary stability point (ESS) (see Tab III), the decision-making process of both sides of the game: on the government side: the government finds that no matter what strategy companies adopt, the expected return of the government's strict supervision is always smaller than that of the non-strict supervision. At this time, the government is more inclined to choose the non-strict supervision. On the enterprise side: On the enterprise side, because the government chose not to supervise strictly, at this time, the expected benefits of strict enterprise governance are less than those of non-strict governance, so enterprises choose non-strict governance. The evolutionary stability strategy is (non-strict supervision, on-strict supervision), and the corresponding evolutionary dynamic phase of the system is shown in Fig 2;

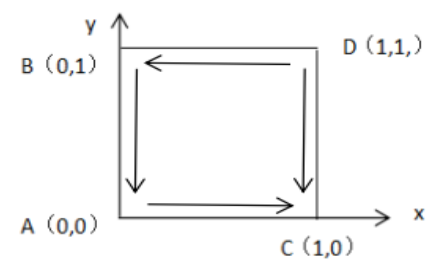

Fig. 3. phase evolution of state c

$\mathrm{c}$ :When in state $\mathrm{c}$, point $\mathrm{D}(1,1)$ is the source point of instability, and point $\mathrm{C}(1,0)$ is the evolutionary stability point (ESS) (see Tab III),the decision-making process of both sides of the game: On the enterprise side: enterprise find that no matter what the government's strategy, the expected return when the enterprise is strict is always smaller than that when the enterprise is not strict, then the enterprise is more inclined to choose non-strict governance. In terms of government, because enterprise choose non-strict management, at this time, the expected benefit of the government's choice of strict supervision strategy is greater than that of the non-strict supervision strategy, so the government chooses strict supervision. The evolutionary stability strategy is (strict supervision, non-strict supervision), and the corresponding evolutionary dynamic phase of the system is shown in Fig 3;

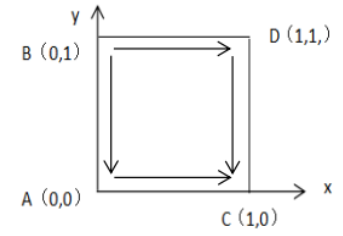

Fig. 4. phase evolution of state d

$\mathrm{d}$ : When in state $\mathrm{d}$, point $\mathrm{B}(0,1)$ is the source point of instability, and point $\mathrm{C}(1,0)$ is the evolutionary stability point (ESS) (see Tab III), the deciston-making process of both sides of the game: On the government side, no matter what strategy enterprise choose, the expected benefits of the government's choice of strict supervision are always greater than those of non-strict supervision, that is, the government tends to choose strict supervision. On the enterprise side: enterprise find that no matter what the government's strategy, the expected return when the enterprise is strict is always smaller than that when the enterprise is not strict, then the enterprise is more inclined to choose non-strict governance. The evolutionary stability strategy is (strict supervision, non-strict supervision), and the corresponding evolutionary dynamic phase of the system is shown in Fig 4;

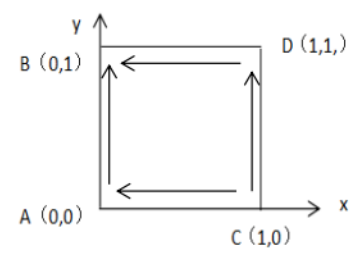

Fig. 5. phase evolution of state e

e: When in state e, point $\mathrm{C}(1,0)$ is the source point of instability, and point $\mathrm{B}(0,1)$ is the evolutionary stability point 
(ESS) (see Tab III), the deciston-making process of both sides of the game: On the government side: the government finds that no matter what strategy companies adopt, the expected return of the government's strict supervision is always smaller than that of the non-strict supervision. At this time, the government is more inclined to choose the non-strict supervision. On the enterprise side: In the aspect of enterprise, no matter what kind of strategy the government chooses, the expected return of enterprise choosing strict governance strategy is always greater than that of non-strict governance, and enterprises tend to choose strict governance. The evolutionary stability strategy is (non-strict supervision, strict supervision), and the corresponding evolutionary dynamic phase of the system is shown in Fig 5;

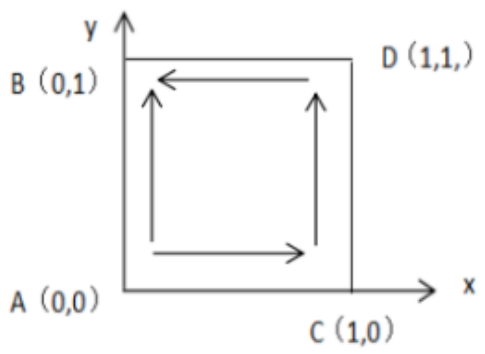

Fig. 6. Phase evolution of state $\mathrm{f}$

$f:$ When in state $f$, point $A(0,0)$ is the source point of instability, and point $\mathrm{B}(0,1)$ is the evolutionary stability point (ESS) (see Tab III), the deciston-making process of both sides of the game: On the enterprise side: In the aspect of enterprise, no matter what kind of strategy the government chooses, the expected return of enterprise choosing strict governance strategy is always greater than that of non-strict governance, and enterprises tend to choose strict governance. For the government, because enterprises choose strict governance strategy, the expected return under strict supervision by the government is less than the expected return without strict supervision, so the government chooses non-strict supervision strategy. The evolutionary stability strategy is (non-strict supervision, strict supervision), and the corresponding evolutionary dynamic phase of the system is shown in Fig 6;

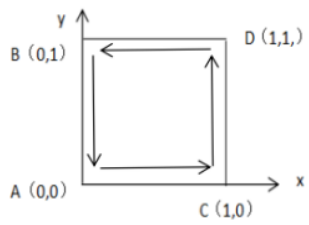

Fig. 7. Phase evolution of state $\mathrm{g}$

$\mathrm{g}$ : When in $\mathrm{g}$ state, it is found that points $\mathrm{A}(1,1), \mathrm{B}(0,1)$, $\mathrm{C}(1,0)$ and $\mathrm{D}(0,0)$ are all saddle points by calculation (see Tab III), the deciston-making process of both sides of the game: On the corporate side, when local government choose a strict supervision strategy, the expected return of enterprise strict governance is greater than that of non-strict governance strategy. Enterprises are more inclined to choose strict governance. When the government chooses the non-strict supervision strategy, the expected return of enterprise strict governance is less than that of the non-strict governance strategy, and enterprise tend to choose the non-strict governance. Therefore, the choice of enterprise strategy will depend on the government's choice of strategy. On the government side, when companies choose strict governance, the expected revenue of the government's strict supervision is less than that of the non-strict supervision, and the government is more inclined to choose the non-strict supervision. When enterprise choose non-strict governance, the expected benefits of strict governance by the government are greater than those of non-strict governance, and the government is more inclined to choose strict governance. In this case, the ESS will not appear in the system, but will fall into a cyclic strategy state: the government chose the strict supervision, enterprise will choose the strict governance, the government see enterprise choose the strict governance, so choose non-strict supervision, when enterprise see the government is non-strict supervision, so choose non-strict governance, the government see enterprise choose non-strict management, the government chooses strict supervision...The strategic choices of both sides of the game change constantly, so that they cannot converge to a certain equilibrium point (see Fig 7);

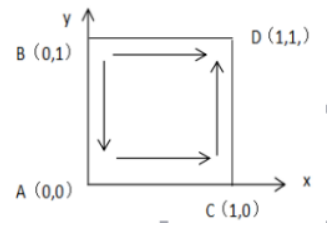

Fig. 8. phase evolution of state $\mathrm{h}$

$\mathrm{h}$ : When in state $\mathrm{i}$, point $\mathrm{B}(0,1)$ is the source point of instability, and point $\mathrm{D}(1,1)$ is the evolutionary stability point (ESS) (see Tab III), the deciston-making process of both sides of the game: On the government side: no matter what kind of strategy the enterprise choose, the expected return of goverment choosing strict supervision strategy is always greater than that of non-strict supervision, and goverment tend to choose strict supervision. On the enterprise side: because the government has chosen a strict supervision strategy, in this case, the expected benefits of strict governance are greater than those of non-strict ones, and the enterprise choose strict governance. The evolutionary stability strategy is (strict supervision, strict governance), and the corresponding evolutionary dynamic phase of the system is shown in Fig 8;

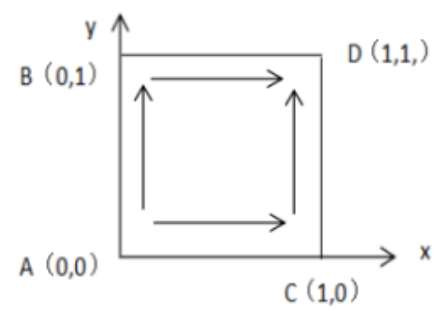

Fig. 9. phase evolution of state $\mathrm{i}$

$\mathrm{i}$ : When in state $\mathrm{j}$, point $\mathrm{A}(0,0)$ is the source point of instability, and point $\mathrm{D}(1,1)$ is the evolutionary stability point (ESS) (see Tab III), the deciston-making process of both sides 
of the game: On the government side: the government finds that no matter what strategy of the enterprise, the expected return of strict supervision by the government is always greater than that of non-strict supervision. At this time, the government is more inclined to choose strict supervision. In the aspect of enterprise, no matter what kind of strategy the government chooses, the expected return of enterprise choosing strict governance strategy is always greater than that of non-strict governance, and enterprises tend to choose strict governance. The evolutionary stability strategy is (strict supervision, strict governance), and the corresponding evolutionary dynamic phase of the system is shown in Fig 9;

Analysis: by comparing the decision-making process and evolutionary stability strategy of the above 10 different states, we found that: When the enterprise's strategy is certain, the factors that influence the government's decision are the difference between the expected return of the strict supervision and the expected return of the non-strict supervision, and the main factors that affect this difference are :The degree of strict supervision $\left(\lambda_{1}\right)$;Standard coefficient of bike sharing parking specification(k);A fine for strict enterprise governance $\left(\mathrm{kh}_{1}\right)$ and A fine for non-strict enterprise governance $\left(\mathrm{kh}_{2}\right)$; The cost of strict supervision $\left(\mathrm{C}_{1}\right)$; Through observation, it is found that the government's choice of strict supervision strategy is inversely proportional to $\lambda_{1}$ and $\mathrm{C}_{1}$, and is directly proportional to $\mathrm{k}, \mathrm{kh}_{1}$ and $\mathrm{kh}_{2}$.

When the government strategy is certain, the factors that influence the enterprise decision are the difference between strict governance and non-strict governance. The main factors that influence this difference are: The degree of strict governance $\left(\lambda_{2}\right)$; The degree of strict supervision $\left(\lambda_{1}\right)$;Standard coefficient of bike sharing parking specification $(\mathrm{k})$; Benefits of strict enterprise governance(L); The initial number of illegal parking bike sharing (e);Cost of strict enterprise governance $\left(C_{2}\right)$; Through observation, it is found that the strict governance strategy chosen by the enterprise is inversely proportional to $\lambda_{2}$ and $\mathrm{C}_{2}$, and is directly proportional to $\mathrm{k}, \lambda_{1}$ and $\mathrm{e}$.

\section{CONCLUSIONS AND SUGGESTIONS}

Based on the current development of bicycle sharing enterprises and the state of government supervision, this paper establishes a stable strategy analysis model between the government and the bike sharing enterprise by using the evolutionary game theory, the study found that the decisionmaking evolution rules of government and enterprises include 9 cases in total. The study shows that the performance coefficient of the government's assessment of corporate governance has no influence on the choice of strategies of both sides of the game. The probability of strict governance can be increased by improving the degree of government supervision and standard coefficient of bikle sharing parking standard, reducing cost of the strict supervision .In the same way, it can increase the probability of strict supervision by improving the standard coefficient of bike sharing parking regulation and reducing the cost of strict supervision. In addition, under certain initial conditions (g), the government and enterprises are trapped in a dead cycle when choosing strategies, which may be the reason why the problem of bike sharing unregulated parking has not been well solved.
In order to improve the government's supervision and enterprise governance, so that bike sharing can develop healthily and benefit the society better, the following policy suggestions can be proposed based on the above research conclusions:(1)The government should strengthen supervision and punishment measures. The government should strengthen supervision and punishment measures to urge enterprises to strictly govern problem of parking of bike sharing, and prevent the government and enterprise from falling into a dead cycle.(2)Scientifically formulate the parking standard coefficient of bike sharing. Scientific formulation and moderate improvement of the parking standard coefficient of bike sharing can not only encourage enterprises to strictly govern but also promote the strict supervision of government. (3) Establish incentive mechanism. Through the establishment of incentive mechanism, to reduce the cost of the enterprise governance, the enterprise are encouraged to strictly manage. (4) Strengthen government supervision technology. Because the supervisors are not at the same level of supervision technology, the supervision cycle is lengthened, which indirectly leads to the increase of supervision cost. Therefore, by strengthening the supervision technology to reduce the supervision cycle, the cost of government supervision is reduced and the confidence of government supervision is increased.

\section{ACKNOWLEDGEMENT}

This research was financially supported by Xi'an Social Science Planning Fund Project (18J161) and China Postdoctoral Science Fund Project (2018M633446).

\section{REFERENCES}

[1] Yijin Zhang, Jinsong Zhang. Evolutionary game between governmental supervision and bike sharing platform [J]. Statistics and decision-making, 2017(23):64-66. (In Chinese)

[2] Site Fu, the improvement of the parking mode of bike sharing-design of sharing house $[\mathrm{J}]$. Journal of jishou university (social science edition), 2017, 38(S2):122-126. (In Chinese)

[3] Lifan Deng, Yonghong Xie, Dingxi Huang. Planning research on bike sharing facilities based on time-space data of cycling [J].2017, 33 (10):82-88. (In Chinese)

[4] Ran Liu, Xuxia Zhang. Negative external governance of bike sharing in urban public space -- interpretation, dilemma and regulatory path [J].2018, 34(01):71-76. (In Chinese)

[5] Liuhua Yang, Dajian Zhu. Analysis on the influencing factors of intention to regulate parking behavior by bike sharing under the framework of the extended planning behavior theory [J]. Population, resources and environment of China, 2018, 28(04):125-133. (In Chinese)

[6] Shenyong Hao. Innovation in the management of bike sharing from the perspective of sharing economy [J]. 2018(03):36-44+110. (In Chinese)

[7] Friedman D.Evolutionary games in economics [J]. Econometrica, 1991( 59) : 637 - 666 . 